\title{
Deposição a Laser de Superliga à Base de Cobalto sobre Aço Inoxidável Austenítico
}

\author{
Marcelo T. Veiga ${ }^{1,2}$ (D), Leandro J. da Silva ${ }^{3}$ (D), Alexsandro Rabelo² (D), Moisés F. Teixeira ${ }^{2}$ (D), Paulo R. A. Bloemer², Guilherme O. Verran ${ }^{1}$ (D) \\ ${ }^{1}$ Universidade do Estado de Santa Catarina - UDESC, Programa de Pós-graduação em Ciências e Engenharia de Materiais - PPEGM, Joinville, SC, Brasil \\ ${ }^{2}$ Instituto Senai de Inovação em Sistemas de Manufatura e Processamento a Laser, Joinville, SC, Brasil \\ ${ }^{3}$ Universidade Federal de Uberlândia - UFU, Faculdade de Engenharia Mecânica - FEMEC, Uberlândia, SC, Brasil
}

Como citar: Veiga MT, Silva L, Rabelo A, Teixeira MF, Bloemer PRA, Verran GO. Deposição a laser de superliga à base de cobalto sobre aço inoxidável austenítico. Soldagem \& Inspeção. 2021;26:e2602. https://doi.org/10.1590/0104-9224/SI26.02

\begin{abstract}
Resumo: O presente trabalho teve como objetivo determinar parâmetros de processamento a laser para deposição de revestimentos de Stellite 6 livres de descontinuidades e com geometria adequada sobre aço inoxidável austenítico. Revestimentos foram depositados com uma fonte de laser de diodo, equipada com um cabeçote coaxial contínuo, utilizando diferentes potências do feixe e velocidades de varredura. A geometria (largura, altura, ondulação e diluição) dos revestimentos foi medida por meio de análise da secção transversal. Esses dados obtidos foram utilizados para a modelagem do processo (superfície de resposta) e para estimar parâmetros otimizados (função desejabilidade), que foram posteriormente verificados experimentalmente. A microestrutura dos revestimentos depositados com os parâmetros otimizados foi caracterizada por microscopia óptica e eletrônica de varredura. A seleção adequada dos parâmetros resultou em revestimentos com bom acabamento, livre de descontinuidades superficiais e baixa diluição. Os resultados mostram que a potência do laser teve efeito significativo sobre a diluição, enquanto a velocidade influenciou na altura da camada depositada. A microestrutura resultante do revestimento é composta por dendritas ricas em cobalto e a região interdendrítica com carbonetos de cromo. Os resultados de dureza estão de acordo com o previsto na literatura.
\end{abstract}

Palavras-chave: Revestimento a laser; Deposição direta de energia; Deposição de superliga; Modelagem de processo Laser; Microestrutura Stellite 6.

\section{Laser Cladding of a Cobalt-Based Superalloy on Austenitic Stainless Steel}

\begin{abstract}
The present work aimed to determine laser processing parameters for deposition of defect-free Stellite 6 coatings and with suitable geometry on austenitic stainless steel. Coatings were deposited with a diode laser source, equipped with a continuous coaxial head, using different beam powers and scanning speeds. The geometry (width, height, undulation and dilution) of the coatings was measured by analyzing the cross section. These obtained data were used to model the process (response surface) and to estimate optimized parameters (function desirability), which were later verified experimentally. The microstructure of the coatings deposited with the optimized parameters was characterized by optical and scanning electron microscopy. The proper selection of parameters resulted in coatings with good surface finish, free of superficial defects and low dilution. The results show that the laser power had a significant effect on the dilution, while the speed influenced the height of the deposited layer. The microstructure resulting from the coating is composed of dendrites rich in cobalt and interdendritic region with chromium carbides. The hardness results are in line with the predicted in the literature.
\end{abstract}

Key-words: Laser cladding; Direct energy deposition; Superalloy deposition; Laser process modeling; Stellite 6 microstructure.

\section{Introdução}

A deposição de revestimentos duros (hardfacing) é uma prática amplamente utilizada para melhorar o desempenho de componentes que operam em condições agressivas, por exemplo: mineração, metalurgia, geração de energia etc. [1-3]. Dentre os vários processos disponíveis, a deposição a laser (laser cladding) tem ganhado cada vez mais aceitação industrial principalmente devido a sua alta densidade de energia, que se reflete em revestimentos com baixa diluição, microestruturas refinadas, pouca distorção e uma reduzida zona afetada pelo calor.

Pelo fato de utilizar material de adição na forma de pó, a deposição de revestimentos a laser possibilita a escolha de uma ampla gama de ligas ou até mesmo a formação de ligas in-situ por meio da mistura de pós, permitindo customizar o revestimento 
de acordo com a aplicação [4-6]. Por este motivo, a aplicação de superligas como revestimento através deste processo se torna ainda mais atrativo.

As superligas são constituídas de ligas de níquel, ferro-níquel ou cobalto e são empregadas em situações nas quais os materiais devem manter suas propriedades mesmo em condições extremas, como temperaturas acima de 540으 [7]. Geralmente, as superligas de níquel são aplicadas quando se deseja eleva resistência à corrosão, já as superligas à base de cobalto para aplicações onde se deseja elevada resistência ao desgaste. Além disso, as ligas de cobalto possuem uma importância estratégica por sua utilização na indústria militar, fabricação de imãs, aços rápidos e metal duro [8].

Dentre as diversas superligas de cobalto desenvolvidas pela Haynes ${ }^{\circledR}$, um das mais empregada é a Stellite $6^{\circledR}$, que possuir uma excelente resistência às várias formas de degradação química e mecânica em temperaturas de até $800^{\circ} \mathrm{C}$, sendo utilizada em muitos processos de hardfacing $[9,10]$. Esta liga de cobalto é constituída de uma matriz austenítica cúbica de face centrada e é endurecida principalmente pela precipitação de carbonetos do tipo $M C, M_{7} C_{3}, M_{6} C$ e $M_{23} C_{6}$ [8], porém, devido às diferentes formas de fabricação, um maior entendimento de suas características como microestrutura, fases e métodos de endurecimento se faz necessário. Com o intuito de evidenciar o crescente interesse no estudo desta liga, a Tabela 1 relaciona algumas das referências mais recentes, nas mais variadas formas de fabricação e aplicação, com seu devido objetivo de estudo.

Tabela 1. Referências de trabalhos acadêmicos que utilizam Stellite 6 como foco de estudo e seus objetivos.

\begin{tabular}{|c|c|c|c|}
\hline Referência & Liga / Substrato & Técnica de deposição & Objetivo \\
\hline $\begin{array}{l}\text { Krell et al. } \\
\quad[11]\end{array}$ & $\begin{array}{l}\text { Ligas de Stellite 1, 6, } 12 \\
\text { e } 21 \text { / Aço baixa liga }\end{array}$ & $\begin{array}{l}\text { Fundido, sinterizado } \\
\text { (HIP) depositado por } \\
\text { GMAW. }\end{array}$ & $\begin{array}{l}\text { Analisar a microestrutura, dureza e desgaste em alta temperatura de } \\
\text { diferentes ligas de Stellite. }\end{array}$ \\
\hline $\begin{array}{l}\text { Wang et al. } \\
\quad[12]\end{array}$ & $\begin{array}{l}\text { Stellite-6 e WC/ Aço } \\
\text { AISI H13 }\end{array}$ & $\begin{array}{l}\text { Revestimento a laser } \\
\quad \text { (laser de fibra) }\end{array}$ & $\begin{array}{c}\text { Avaliar o efeito da adição de WC sobre a resistência a fadiga térmica } \\
\text { do revestimento de Stellite } 6 .\end{array}$ \\
\hline $\begin{array}{l}\text { Wu et al. } \\
\quad[13]\end{array}$ & $\begin{array}{l}\text { Stellite 6/ Aço } \\
\text { 24CrNiMo }\end{array}$ & $\begin{array}{l}\text { Revestimento a laser } \\
\quad \text { (laser de fibra) }\end{array}$ & $\begin{array}{l}\text { Avaliar o efeito do tratamento térmico sobre a propagação de trincas } \\
\text { de fadiga térmica. }\end{array}$ \\
\hline $\begin{array}{c}\text { Karimi et al } \\
.[14]\end{array}$ & Stellite $6 /$ Stellite 6 & $\begin{array}{l}\text { Fundido e } \\
\text { sinterizados (HIP) }\end{array}$ & $\begin{array}{l}\text { Investigar a resistência a corrosão da liga fundida e fabricada por HIP } \\
\text { em um ambiente simulado de alta temperatura e pH básico. }\end{array}$ \\
\hline $\begin{array}{l}\text { Mostafaei } \\
\text { et al. [15] }\end{array}$ & Stellite $6 /$ Stellite 6 & $\begin{array}{l}\text { Binder jet sinterizado } \\
\text { (Manufatura aditiva) }\end{array}$ & $\begin{array}{c}\text { Avaliar a microestrutura e dureza da liga Stellite } 6 \text { processada por } \\
\text { Binder Jet e posteriormente sinterizada. }\end{array}$ \\
\hline $\begin{array}{l}\text { Brownlie et } \\
\text { al. [16] }\end{array}$ & Stellite 6/ Aço baixa liga & $\begin{array}{l}\text { GTAW alimentado } \\
\text { com arame quente }\end{array}$ & $\begin{array}{c}\text { Avaliar o efeito da nitretação sobre o desgaste a corrosão de } \\
\text { revestimentos de Stellite } 6 .\end{array}$ \\
\hline $\begin{array}{l}\text { Ding et al. } \\
\quad[17]\end{array}$ & $\begin{array}{l}\text { Mistura de ligas Stellite } \\
\text { (S3 e S21) /Aço } \\
\text { inoxidável AISI } 316\end{array}$ & $\begin{array}{l}\text { Revestimento a laser } \\
\text { (laser de diodo } \\
\text { associado a fibra) }\end{array}$ & $\begin{array}{c}\text { Foram estudadas e comparadas a microestrutura, dureza e resistência } \\
\text { ao desgaste por deslizamento da mistura de ligas de Stellite com o } \\
\text { Stellite } 6 \text {, todas depositadas a laser. }\end{array}$ \\
\hline $\begin{array}{l}\text { Houdková } \\
\text { et al. [18] }\end{array}$ & Stellite 6/ Aço carbono & $\begin{array}{l}\text { Aspersão térmica } \\
\text { (HVOF) e } \\
\text { revestimento a laser }\end{array}$ & $\begin{array}{c}\text { Avaliar a microestrutura de revestimentos depositados por HVOF e } \\
\text { tratadas e laser e depositadas a laser. }\end{array}$ \\
\hline $\begin{array}{l}\text { Li et al. } \\
\text { [19] }\end{array}$ & $\begin{array}{l}\text { Stellite- } 6 \text { e WC/ Aço } \\
\text { AISI } 1045\end{array}$ & $\begin{array}{l}\text { Revestimento a laser } \\
\text { supersônico (SLD) }\end{array}$ & $\begin{array}{c}\text { Analisar como o processo SLD pode interferir na tensão residual, } \\
\text { oxidação, transformação de fases e crescimento de grãos no } \\
\text { revestimento. }\end{array}$ \\
\hline $\begin{array}{l}\text { Bartkowski } \\
\text { e Kinal [1] }\end{array}$ & $\begin{array}{l}\text { Stellite- } 6 \text { e WC/ Aço } \\
\text { baixo carbono }\end{array}$ & $\begin{array}{l}\text { Revestimento a laser } \\
\text { (laser de disco } \\
\text { Yb:YAG) }\end{array}$ & $\begin{array}{l}\text { Avaliar o impacto da adição de WC sobre a microestrutura, dureza e } \\
\text { resistência à corrosão de revestimentos de Stellite } 6 \text {. }\end{array}$ \\
\hline $\begin{array}{c}\text { Bartkowski } \\
\text { e } \\
\text { Bartkowska } \\
\text { [5] }\end{array}$ & $\begin{array}{l}\text { Stellite- } 6 \text { e WC/ Aço } \\
\text { com adição de boro }\end{array}$ & $\begin{array}{c}\text { Revestimento a laser } \\
\text { (laser de disco } \\
\text { Yb:YAG) }\end{array}$ & Avaliação de desempenho do revestimento em ambiente relevante. \\
\hline $\begin{array}{l}\text { Bartkowski } \\
\text { et al. [2] }\end{array}$ & $\begin{array}{l}\text { Stellite- } 6 \text { e WC/ Aço } \\
\text { baixo carbono }\end{array}$ & $\begin{array}{c}\text { Revestimento a laser } \\
\text { (laser de disco } \\
\text { Yb:YAG) }\end{array}$ & $\begin{array}{l}\text { Avaliar a microestrutura, resistência ao desgaste e a corrosão } \\
\text { eletroquímica de revestimentos de Stellite } 6 \text { com adição de WC. }\end{array}$ \\
\hline
\end{tabular}

No caso da deposição a laser de revestimentos de Stellite-6, a seleção de parâmetros é um fator chave para obtenção de revestimentos íntegros que atendam aos requisitos de aplicação. Geralmente, e seleção de parâmetros é feita experimentalmente através de "tentativa e erro", o que pode gerar custos significativos devido aos elevados custos dessa liga. Por isso, métodos para estimar parâmetros de deposição são de grande interesse comercial. Vários trabalhos já endereçaram esse problema e diferentes abordagens foram propostas, sendo que a modelagem estatística se mostrou um método eficaz e com baixo custo computacional. Porém, os modelos estatísticos são válidos apenas para as condições nas quais foram desenvolvidos. Logo, para cada condição de processamento (equipamento e material) novos modelos são necessários. 
Nesse sentido, o presente trabalho tem por objetivo estimar parâmetros de processamento a laser para deposição de revestimentos de Stellite 6 livres de descontinuidades e com geometria adequada sobre aço inoxidável austenítico. 0 material depositado foi analisado na sua seção transversal através da microscopia óptica, suas propriedades foram inseridas em um modelo matemático de superfície de resposta, para permitir o modelamento da região de processamento. Os parâmetros otimizados foram obtidos a partir da função desejabilidade e posteriormente testados. A caracterização dos revestimentos foi realizada utilizando ensaios de dureza, diferentes formas de microscopia e espectroscopia dispersiva de raios-X (EDS).

\section{Materiais e Métodos}

Os ensaios de deposição foram realizados em uma máquina com controle de comando numérico (CNC) com 5 graus de liberdade da fabricante PRECO, apresentada na Figura 1, que utiliza uma fonte laser de diodo da fabricante Laserline modelo LDF6000-60VGP. O laser gerado é transmitido por uma fibra ótica até um cabeçote de deposição Fraunhofer Coax 8 . A Tabela 2 sumariza as condições de deposição utilizadas neste trabalho, condições estas que foram escolhidas de dentro de uma janela de processamento desenhada com experimentos preliminares, resultando assim em um experimento fatorial completo de 3 valores de potência, 3 valores de velocidade de deposição, com Distancias entre Centros de Cordões (DECC) e taxa de alimentação de pó constantes.
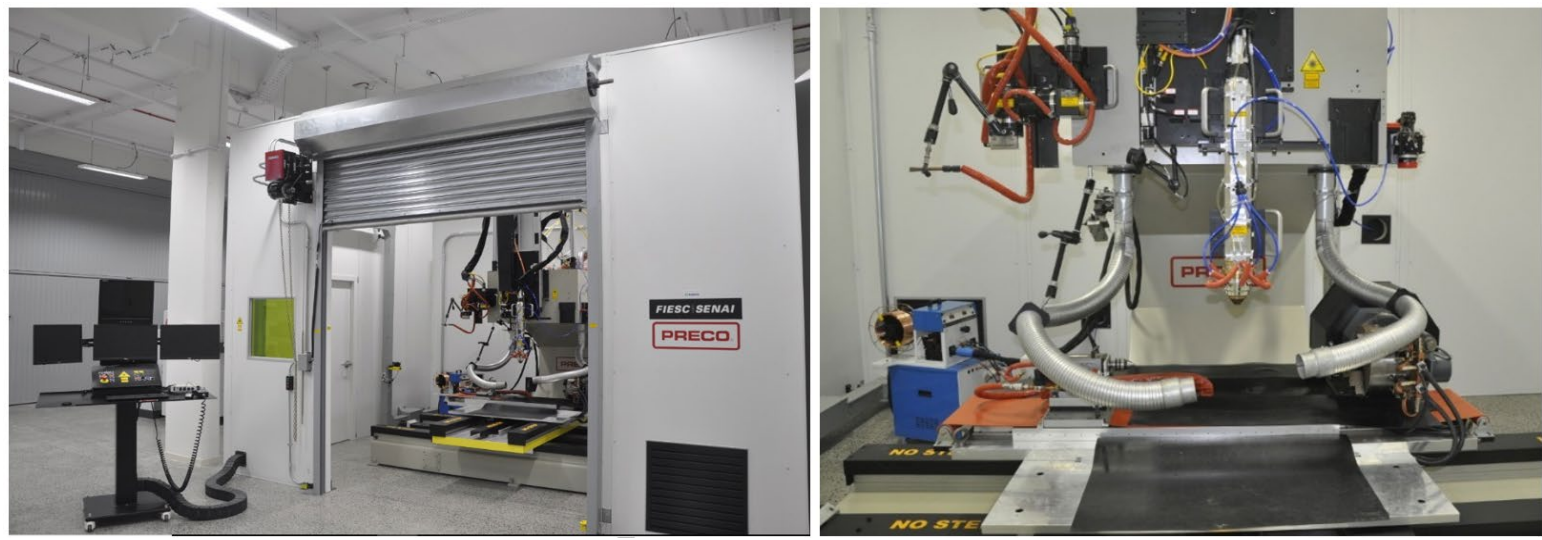

Figura 1. Equipamento de deposição.

Tabela 2. Condições experimentais de deposição utilizadas.

\begin{tabular}{cc} 
Tipo de bocal & Coaxial de alimentação continua \\
Diâmetro focal do feixe $[\mathrm{mm}]$ & 5 \\
Distância de trabalho $[\mathrm{mm}]$ & 15 \\
Potência do feixe $[\mathrm{W}]$ & $2400-3400-4200$ \\
Velocidade de deposição $[\mathrm{mm} / \mathrm{min}]$ & $1200-1600-2000$ \\
Distancias entre centros de cordões (DECC) $[\mathrm{mm}]$ & 2,7 \\
Taxa de alimentação [g/min] & 40 \\
Gás de proteção e arraste $[\mathrm{L} / \mathrm{min}]$ & Argônio a 15 e 6 \\
Número de cordões paralelos & 10 \\
Estratégia de deposição & bidirecional contínuo \\
\hline
\end{tabular}

Os revestimentos foram depositados em substrato do aço inoxidável AISI 316L com dimensões de 16x60x250 mm, utilizando pó metálico MetcoClad $6{ }^{\circledR}$ da fabricante Oerlikon Metco ${ }^{\circledR}$, comumente referenciado como Stellite $6{ }^{\circledR}$, atomizado a gás. As composições químicas nominais do substrato e do material de adição estão apresentadas na Tabela 3.

Tabela 3. Composição química nominal do substrato e material de adição.

\begin{tabular}{|c|c|c|c|c|c|c|c|c|c|}
\hline \multirow{2}{*}{ AISI 316L } & $\mathrm{Fe}$ & $\mathrm{Cr}$ & C & $\mathbf{N i}$ & Mn & Mo & Si & $\mathbf{P}$ & $\mathbf{S}$ \\
\hline & Bal. & 16,00 & 0,02 & 11,00 & 1,20 & 2,00 & 0,50 & 0,03 & 0,00 \\
\hline \multirow{2}{*}{$\begin{array}{c}\text { MetcoClad } 6 \\
\text { (Stellite 6) }\end{array}$} & Co & $\mathrm{Cr}$ & C & Si & $w$ & $\mathrm{Fe}$ & & & \\
\hline & Bal. & 28,00 & 1,00 & 0,65 & 2,50 & 0,06 & Valores & centa & n massa \\
\hline
\end{tabular}


A distribuição granulométrica dos pós metálicos foi verificada através da técnica de análise dinâmica de imagem, utilizando um equipamento Particle Insight da Analyse Systems. Na Tabela 4 estão apresentados os valores de distribuição de tamanho das partículas (diâmetro equivalente a área da silhueta da partícula). Conforme apresentado na Figura 2, a morfologia do material de adição tende a ser esférica, com a presença de partículas satélites (Figura 2a, b). A análise da seção transversal das partículas revela poucos poros internos (característicos da atomização a gás) e microestrutura dendrítica (Figura 2c, d).

Tabela 4. Distribuição granulométrica do pó metálico.

\begin{tabular}{ccc}
\hline Dv $10 \%[\mu \mathrm{m}]$ & Dv 50\% $[\mu \mathrm{m}]$ & Dv 90\% [ $\mu \mathrm{m}]$ \\
60,3 & 82,8 & 114,6 \\
\hline
\end{tabular}
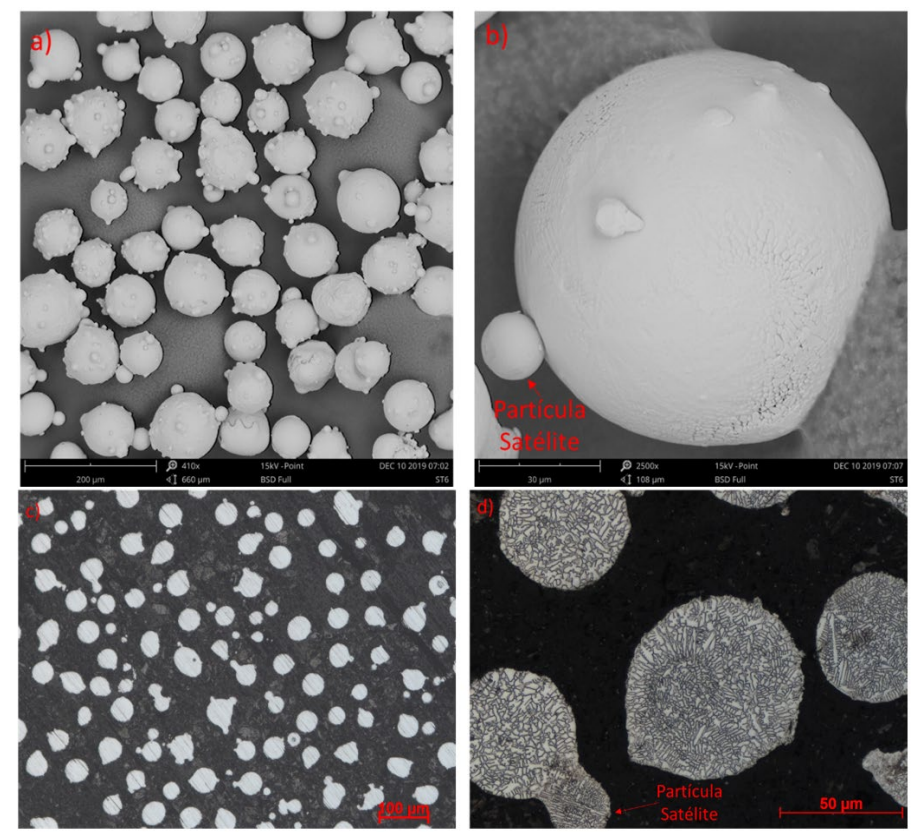

Figura 2. Caracterização do Pó metálico: (a-b) morfologia da partícula via MEV e (c-d) análise da secção transversal via MO.

Após a deposição dos revestimentos, a presença de descontinuidades superficiais foi verificada por meio do ensaio de Líquido Penetrante (LP). Os parâmetros geométricos ilustrados na Figura 3 (área total da deposição, área superior da deposição, altura de camada e altura média de vale) foram medidos utilizando o software ImageJ a partir das macrografias da secção transversal dos revestimentos. A diluição e a ondulação foram medidas usando o método das áreas, conforme Equação 1 e 2. Os parâmetros geométricos (variáveis dependentes) foram correlacionados com os parâmetros de processamentos a laser (variáveis independentes) por meio da técnica de superfície de resposta utilizando o software RStudio. Posteriormente foram determinados os parâmetros otimizados utilizando a função desejabilidade [20], que foram experimentalmente verificados.

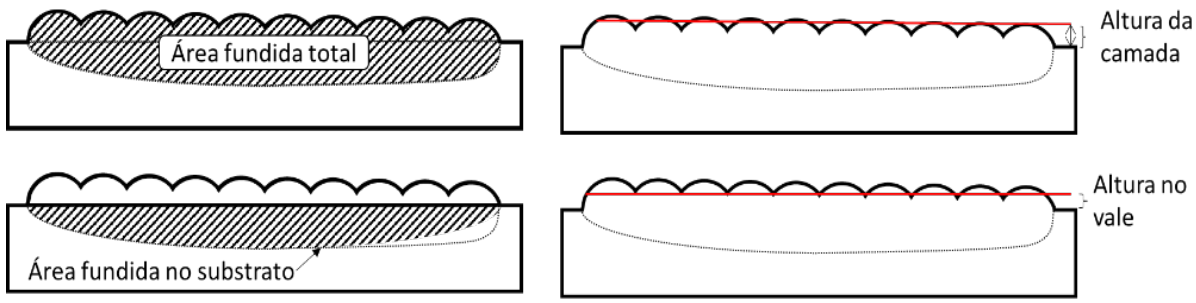

Figura 3. Representação esquemática dos parâmetros geométricos.

Diluição $[\%]=\frac{\text { Área fundida no substrato }}{\text { Área fundida total }}$ 
As microestruturas dos revestimentos obtidos nos experimentos foram caracterizadas por meio de microscopia óptica (MO) e microscopia eletrônica de varredura por emissão de campo (MEV-FEG). As amostras foram preparadas usando o método tradicional de preparação metalográfica (corte, lixamento e polimento), para as observações usando MO foram atacadas por imersão em água regia (concentração de 3:1 de $\mathrm{HCl}$ para $\mathrm{HNO}_{3}$ ) por aproximadamente 60 segundos. Microanálises qualitativas da composição química foram realizadas por EDS na amostra sem ataque. Adicionalmente foram realizados os perfis de dureza na seç̧ão transversal dos revestimentos.

\section{Resultados e Discussão}

De forma geral, todas as condições de deposição resultaram em cordões contínuos e sem ocorrência de desplacamento do substrato. O quadro da Figura 4 compila os resultados dos ensaios de líquido penetrante. Indicações mais notáveis foram observadas para os revestimentos depositados com potência de $4200 \mathrm{~W}$ e velocidades de 1200 e $1600 \mathrm{~mm} / \mathrm{min}$, ou seja, as condições com maior energia de linha $(\mathrm{J} / \mathrm{mm})$, como indicado.

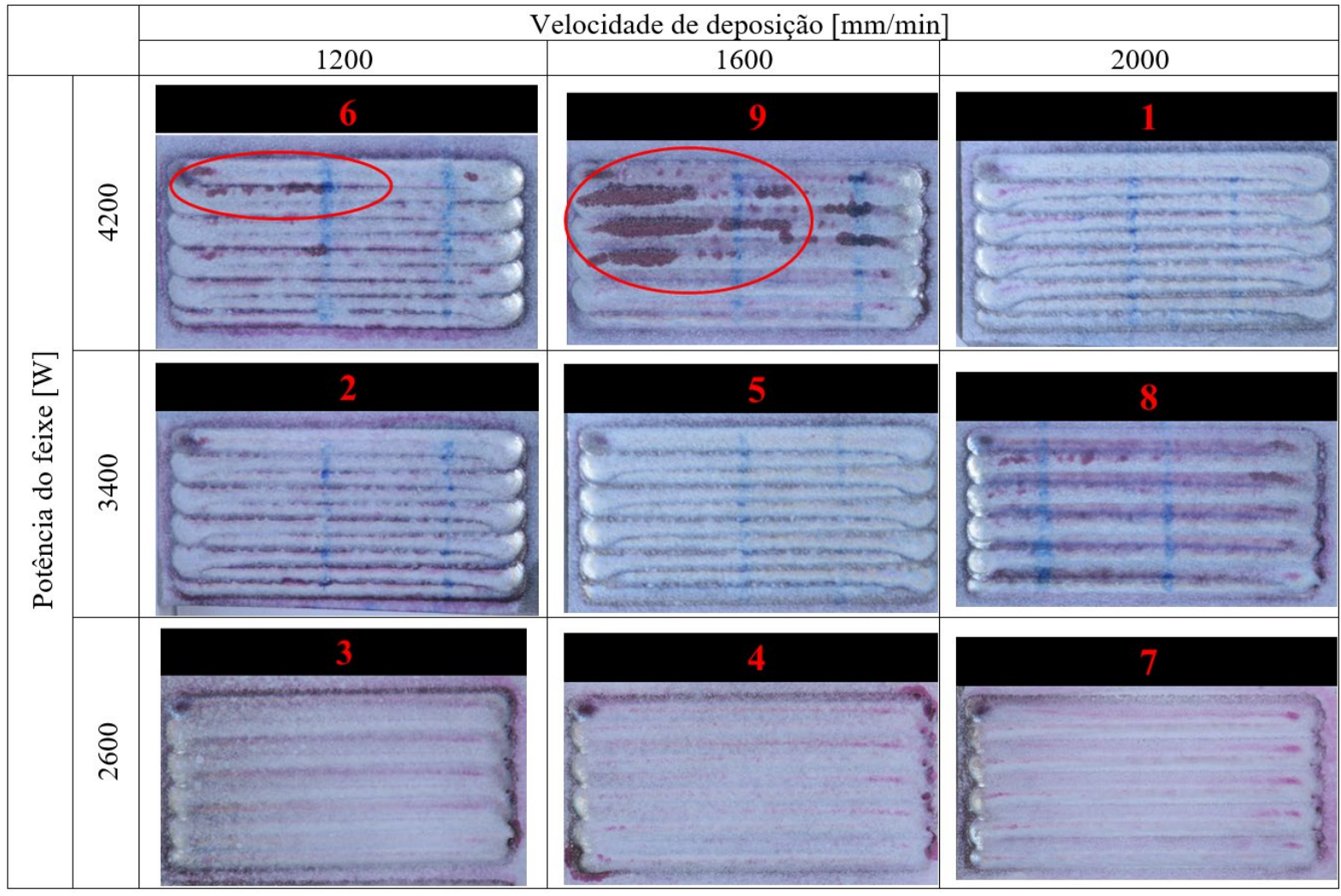

Figura 4. Ensaio de líquidos penetrantes.

As Figura 5 e 6 apresentam as seções transversais nas quais foi possível observar as correlações mais influentes dos parâmetros sob as características geométricas do revestimento. Assim como observado nos estudos realizados por Zhong et al. [21], para uma mesma velocidade de deposição, ao se aumentar a potência do feixe de laser, tanto a penetração como a diluição dos revestimentos aumentam. Desta forma, conforme apresentado na Figura 5 onde a velocidade de $1200 \mathrm{~mm} / \mathrm{min}$ é mantida constante, ao se aumentar a potência de 2600 para $4200 \mathrm{~W}$ observa-se um aumento na diluição do revestimento. De forma análoga, a Figura 6 apresenta uma condição geral em que fixando uma mesma potência e aumentando a velocidade ocorre uma diminuição da diluição e da altura média da camada depositada. Na Figura 6 também estão indicadas as trincas provenientes da alta densidade de energia, reforçando o resultado obtido no ensaio de LP da Figura 4. A maior quantidade de descontinuidades nas camadas com maior aporte de energia pode estar relacionada com o maior nível de tensões residuais (maior volume fundido). Resultados semelhantes são reportados na literatura, como exemplo podemos citar o estudo Lupoi et al. [22]. 


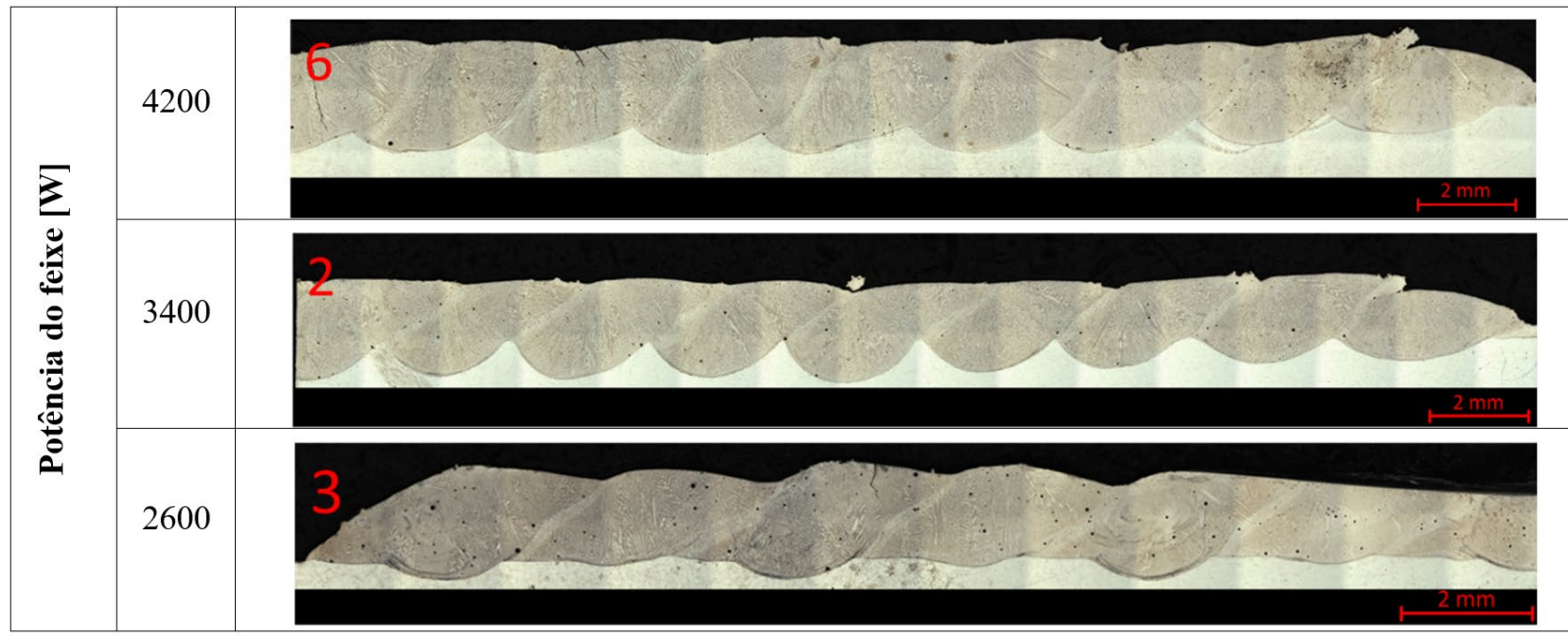

Figura 5. Caso típico do efeito do aumento da potência do laser para a uma dada velocidade de deposição sobre as características geométricas dos revestimentos, velocidade de deposição fixada de $1200 \mathrm{~mm} / \mathrm{min}$.

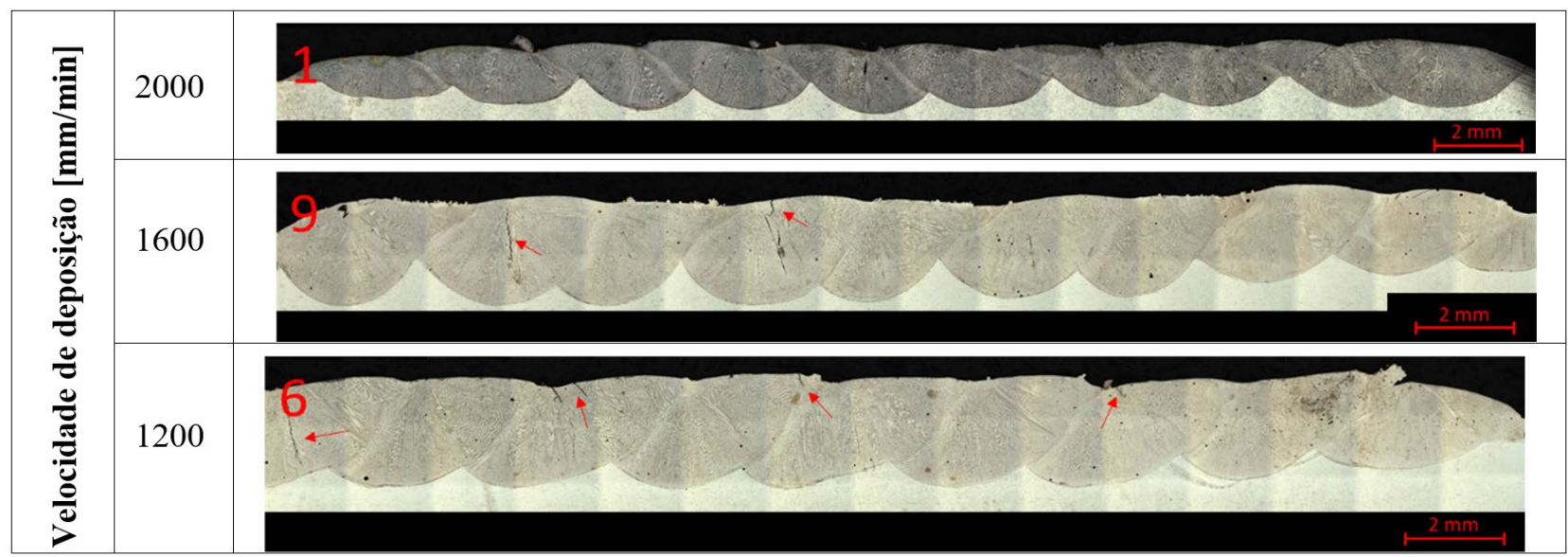

Figura 6. Caso típico do efeito do aumento da velocidade de deposição para uma dada potência do feixe laser sobre as características geométricas dos revestimentos, potência fixada de $4200 \mathrm{~W}$.

Na Tabela 5 estão sumarizados em ordem de fabricação os parâmetros utilizados nos experimentos de deposição, assim como as características geométricas medidas de cada revestimento. Estas medições foram posteriormente utilizadas para elaboração de superfícies de resposta.

Tabela 5. Resultados das medições dos parâmetros geométricos dos revestimentos.

\begin{tabular}{cccccccc}
\hline $\begin{array}{c}\text { Ordem de } \\
\text { fabricação }\end{array}$ & Potência [W] & Velocidade [mm/min] & DEC [mm] & $\begin{array}{c}\text { Vazão } \\
{[\mathrm{g} / \mathrm{min}]}\end{array}$ & $\begin{array}{c}\text { Diluição } \\
{[\%]}\end{array}$ & $\begin{array}{c}\text { Ondulação } \\
{[\mathrm{mm}]}\end{array}$ & $\begin{array}{c}\text { Altura de } \\
\text { camada } \\
{[\mathrm{mm}]}\end{array}$ \\
\hline 1 & 4200 & 2000 & 2,7 & 40 & 44,6 & 0,27 & 0,82 \\
2 & 3400 & 1200 & 2,7 & 40 & 28,9 & 0,15 & 1,12 \\
3 & 2600 & 1200 & 2,7 & 40 & 11,5 & 0,26 & 1,41 \\
4 & 2600 & 1600 & 2,7 & 40 & 2,5 & 0,25 & 1,01 \\
5 & 3400 & 1600 & 2,7 & 40 & 35,9 & 0,15 & 1,24 \\
6 & 4200 & 1200 & 2,7 & 40 & 23,1 & 0,14 & 1,61 \\
7 & 2600 & 2000 & 2,7 & 40 & 8,3 & 0,24 & 0,87 \\
9 & 3400 & 2000 & 2,7 & 40 & 30,2 & 0,15 & 0,82 \\
\hline
\end{tabular}




\subsection{Superfície de respostas}

Na Figura 7 são apresentadas as superfícies de resposta para a diluição, altura média de camada e ondulação de camada em função da potência do feixe e da velocidade de deposição. As Equações 3, 4 e 5 são correspondentes a essas superfícies. A Tabela 6 sumariza o efeito das variáveis independentes (parâmetro de processamento) sobre as variáveis dependentes (propriedades do revestimento). Os comportamentos observados corroboram a literatura corrente; como por exemplo os resultados apresentados por Oliveira et al. [23] em seu estudo sobre a deposição a laser de Inconel sobre aço carbono via laser cladding.
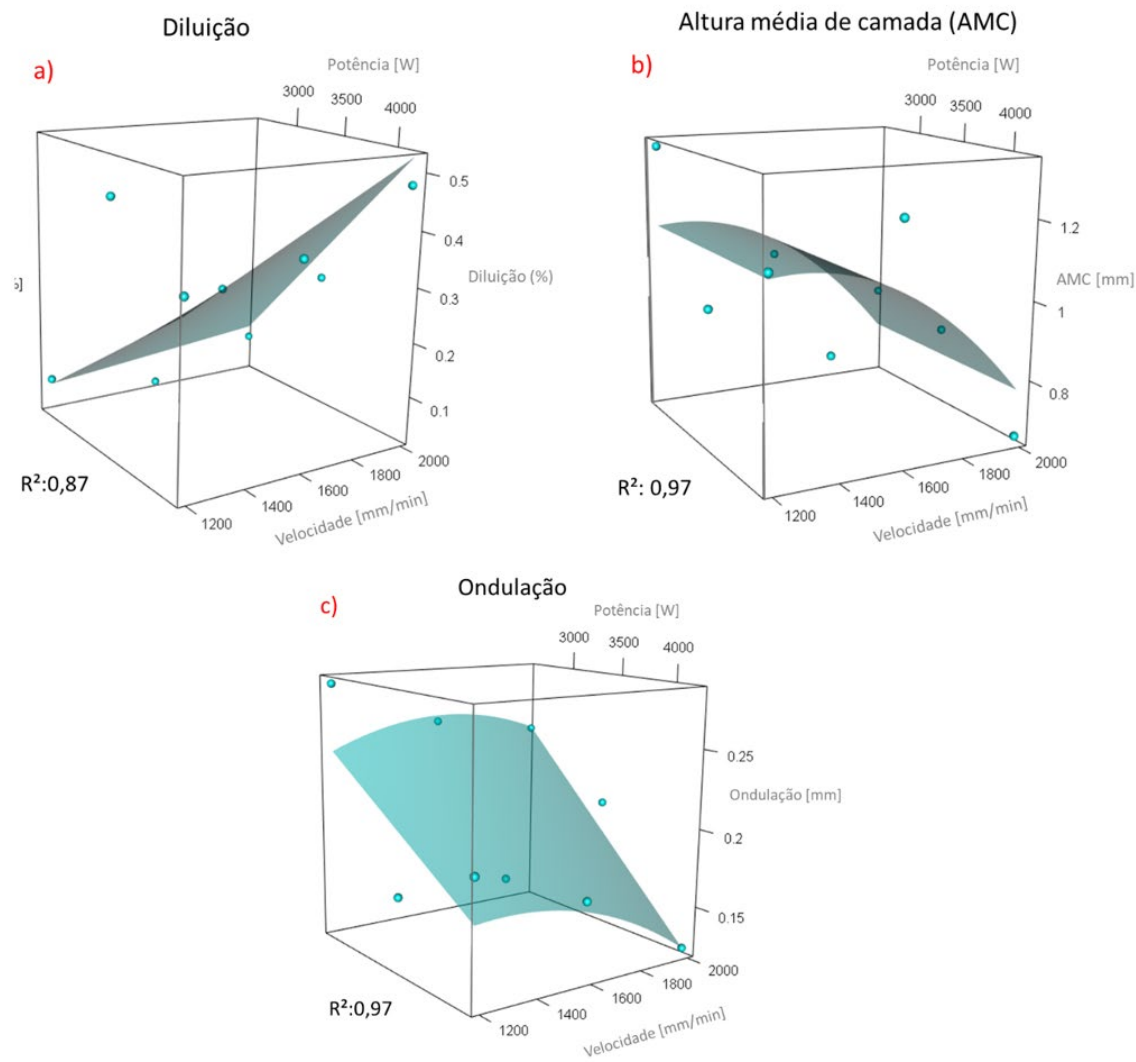

Figura 7. Superfície de respostas para a (a) diluição, (b) altura média da camada e (c) ondulação em função da potência do feixe e velocidade de deposição.

Diluição $[\%]=9,60 \cdot 10^{-6} \cdot P \cdot V-2,20 \cdot 10^{-2} \cdot \mathrm{V}$

$A M C[\mathrm{~mm}]=-8,24 \cdot 10^{-7} \cdot \mathrm{V}^{2}+2,06 \cdot 10^{-3} \cdot \mathrm{V}$

Ondulação $[\mathrm{mm}]=-7,53 \cdot 10^{-8} \cdot \mathrm{V}^{2}-5,46 \cdot 10^{-8} \cdot P \cdot V+3,82 \cdot 10^{-4} \cdot \mathrm{V}$

Onde:

$P$ é a potência do feixe $[W]$ e

$\checkmark$ é a velocidade de deposição [ $\mathrm{mm} / \mathrm{min}]$.

Tabela 6. Efeito do parâmetro de entrada sobre variável de resposta.

\begin{tabular}{cccc}
\hline & Diluição & Altura média da camada & Ondulação da camada \\
个 Potência do feixe $[\mathrm{W}]$ & $\uparrow$ & $=$ & $\downarrow$ \\
$\uparrow$ Velocidade de deposição $[\mathrm{mm} / \mathrm{min}]$ & $\downarrow$ & $\downarrow$ & $=$ \\
\hline
\end{tabular}
Obs: “个” aumenta, " $\downarrow$ " reduz e "=" sem efeito significativo. 


\subsection{Otimização numérica dos parâmetros de deposição}

Para a obtenção dos parâmetros otimizados de revestimento, foram utilizados os modelos levantados experimentalmente (superfícies de resposta) os quais foram alvo de uma otimização numérica por meio da função desejabilidade, proposta por Derringer e Suich [20]. Na Tabela 7 estão sumarizadas coeficientes de otimização onde I, T e S representam respectivamente o limite inferior, o alvo e o limite superior para cada resposta desejada. Essa faixa de parâmetros esperados foi estimada a partir de dados da literatura [18], [24]. Já os parâmetros $s$ e $t$ representam os coeficientes de sensibilidade para o limite inferior e superior para cada variável, respectivamente. Esses coeficientes de sensibilidade são uma tolerância do alvo, de forma que quanto maior esses coeficientes, mais apertada a tolerância. A Figura 8 ilustra a função desejabilidade para cada variável de resposta.

Tabela 7. Parâmetros e coeficientes utilizados na função desejabilidade.

\begin{tabular}{cccccccc}
\hline Resposta & Objetivo da otimização & $\boldsymbol{I}$ & $\boldsymbol{T}$ & $\boldsymbol{S}$ & $\boldsymbol{s}$ & $\boldsymbol{t}$ \\
Diluição [\%] & Alvo & 3 & 10 & 12 & 0,2 & 1,5 \\
Altura de camada [mm] & Alvo & 0,8 & 1 & 1,5 & 0,2 & 0,2 \\
Ondulação [mm] & Minimização & 0 & 0 & 0,4 & - & 0,35 \\
\hline
\end{tabular}


Figura 8. Curvas de desejabilidade para (a) diluição, (b) altura média e (c) ondulação da camada.

A Tabela 8 apresenta os valores calculados para os parâmetros de deposição obtidos através da iteração de valores desejados, este cálculo é realizado sobre os modelos para a obtenção de um conjunto de propriedades geométricas que satisfizeram a função desejabilidade. Adicionalmente, na Tabela 9 estão presentes os valores das propriedades geométricas calculadas do revestimento computados para um revestimento realizado com os valores da Tabela 8 . Através de uma análise preliminar dos parâmetros de deposição estimados, verifica-se que eles são compatíveis com os parâmetros utilizados nos experimentos que geraram a superfície de resposta (Figura 7), e, portanto, apresentam boa chance de estar em concordância com os resultados experimentais.

Tabela 8. Parâmetros de deposição estimados pela otimização do modelo.

$\begin{array}{cc}\text { Potência [W] } & 3100 \\ \text { Velocidade de deposição [mm/min] } & 1420\end{array}$

Tabela 9. Propriedades geométricas calculadas através da função desejabilidade.

\begin{tabular}{cc}
\hline Parâmetro geométrico & Valor desejável obtido \\
Diluição [\%] & 11,1 \\
Altura da camada [mm] & 1,15 \\
Ondulação [mm] & 0,15 \\
\hline
\end{tabular}

\subsection{Verificação experimental dos parâmetros otimizados}

O revestimento depositado utilizando os parâmetros otimizados apresenta um bom aspecto visual e nenhuma indicação de poros e trincas na sua superfície, como pode ser verificado na Figura 9 através do teste de líquidos penetrantes. Além disso, o revestimento apresenta uma altura regular (baixa ondulação), baixa diluição e ausência de falta de fusão, como pode ser observado na Figura 10 e 
Tabela 10. De Oliveira et al. [23] menciona níveis de diluição entre 5 e 30\%, portanto o nível de diluição de $13 \%$ observado nos testes de validação está dentro da faixa típica do processo de deposição de revestimentos a laser. Apesar de valores mais baixos serem reportados na literatura, é importante ter em mente que além da baixa diluição, é desejável que os revestimentos sejam livres de descontinuidades como trincas e falta de fusão, bem como geometria adequada (baixa ondulação e boa concordância geométrica).

Apesar de efetivamente não estudar a ondulação dos revestimentos De Oliveira et al. [23] sugere que seja feita uma relação à distância entre centro de cordões com o ângulo de molhabilidade para evitar as diferenças pronunciadas entre picos e vales. Porém a ondulação encontrada no estudo representa menos de $15 \%$ da altura de camada obtida, em outras palavras poderia se dizer que uma usinagem mínima seria necessária para planificar a superfície do revestimento. Além disso, é possível identificar pouca presença de poros na seção transversal da amostra, com apenas $0,42 \%$ de vazios, valor considerado como insignificante segundo a norma ASTM E2109 [25] para revestimentos fabricados por processo semelhante. E ainda devido a morfologia circular dos poros (baixo efeito de entalhe), estima-se eles sejam pouco nocivos ao desempenho dos revestimentos.
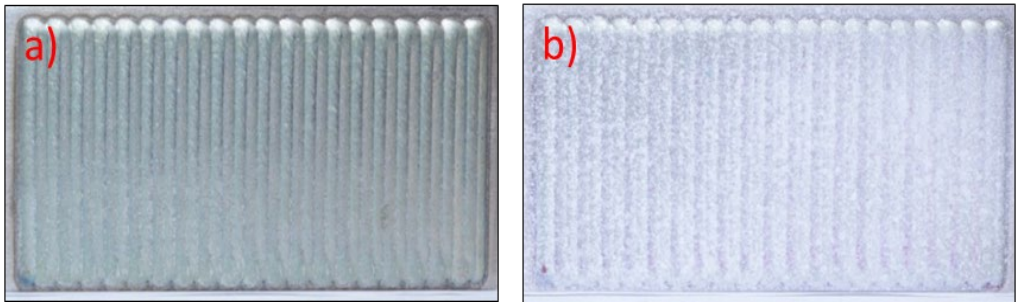

Figura 9. Vista superior do (a) revestimento processado utilizando os parâmetros otimizados e (b) ensaio de líquidos penetrantes da camada depositada sem indicações.

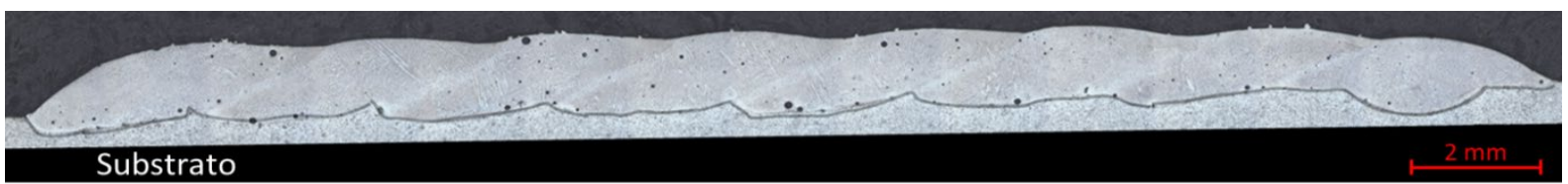

Figura 10. Seção transversal do revestimento obtido no experimento de verificação.

Tabela 10. Diluição, altura de camada e ondulação do revestimento de verificação.

\begin{tabular}{ccc}
\hline Parâmetro geométrico & Valor observado \\
Diluição [\%] & 13,1 \\
Altura da camada [mm] & 1,14 \\
Ondulação [mm] & 0,16 \\
\hline
\end{tabular}

A dureza da camada foi medida na seção transversal dos revestimentos, partindo do topo em direção ao substrato, como mostrado na Figura 11. Não foram observadas variações significativas na dureza do revestimento ao longo de sua altura. A dureza média do revestimento foi de $495 \mathrm{HV}_{0,5}$, corroborando os resultados reportados na literatura para condições semelhantes de processamento [24,26-28].

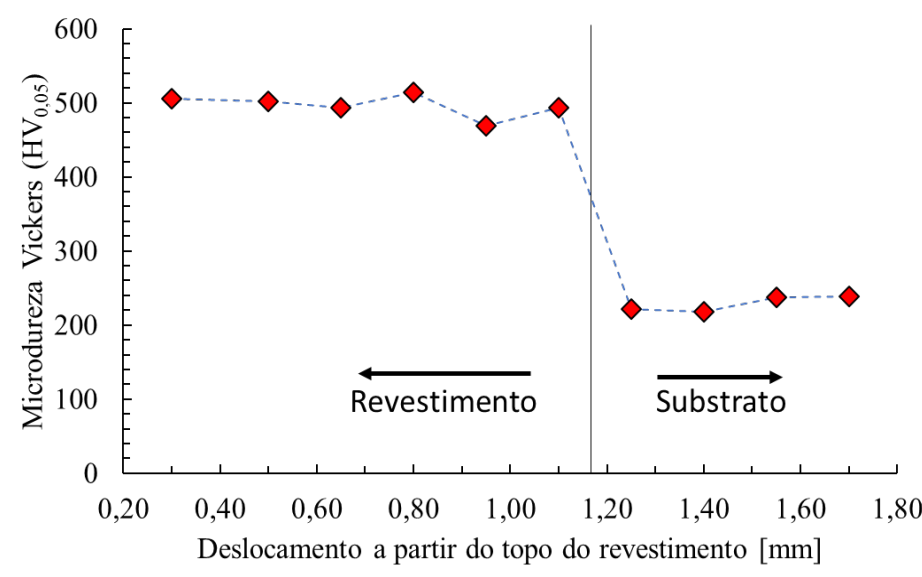

Figura 11. Micro dureza Vickers ao longo da camada depositada. 
A variação da microestrutura ao longo da altura do revestimento é apresentada na Figura 12. Observa-se que junto a linha de fusão (base) a estrutura de solidificação tende a ser planar-celular. Essa variação é comumente observada em ligas que não sofrem transformações no estado sólido, como as ligas de cobalto [2,12]. Em direção ao centro a estrutura de solidificação evolui para colunar dendrítica (meio) e próximo ao topo, tende a ser equiaxial [29,30]. Essa variação da estrutura de solidificação pode ser explicada considerando a variação do parâmetro $G / R$, i.e., a razão entre o gradiente de temperatura (G) e a velocidade de solidificação (R). Segundo Kou [31], junto a linha de fusão, G é elevado e R é baixa, então G/R é elevado o que corresponde a uma estrutura planar. A medida que a poça vai solidificando (caminhando em direção ao topo) o parâmetro $G / R$ tende a diminuir e a estrutura de solidificação passa por celular, colunar e equiaxial dendrítica.

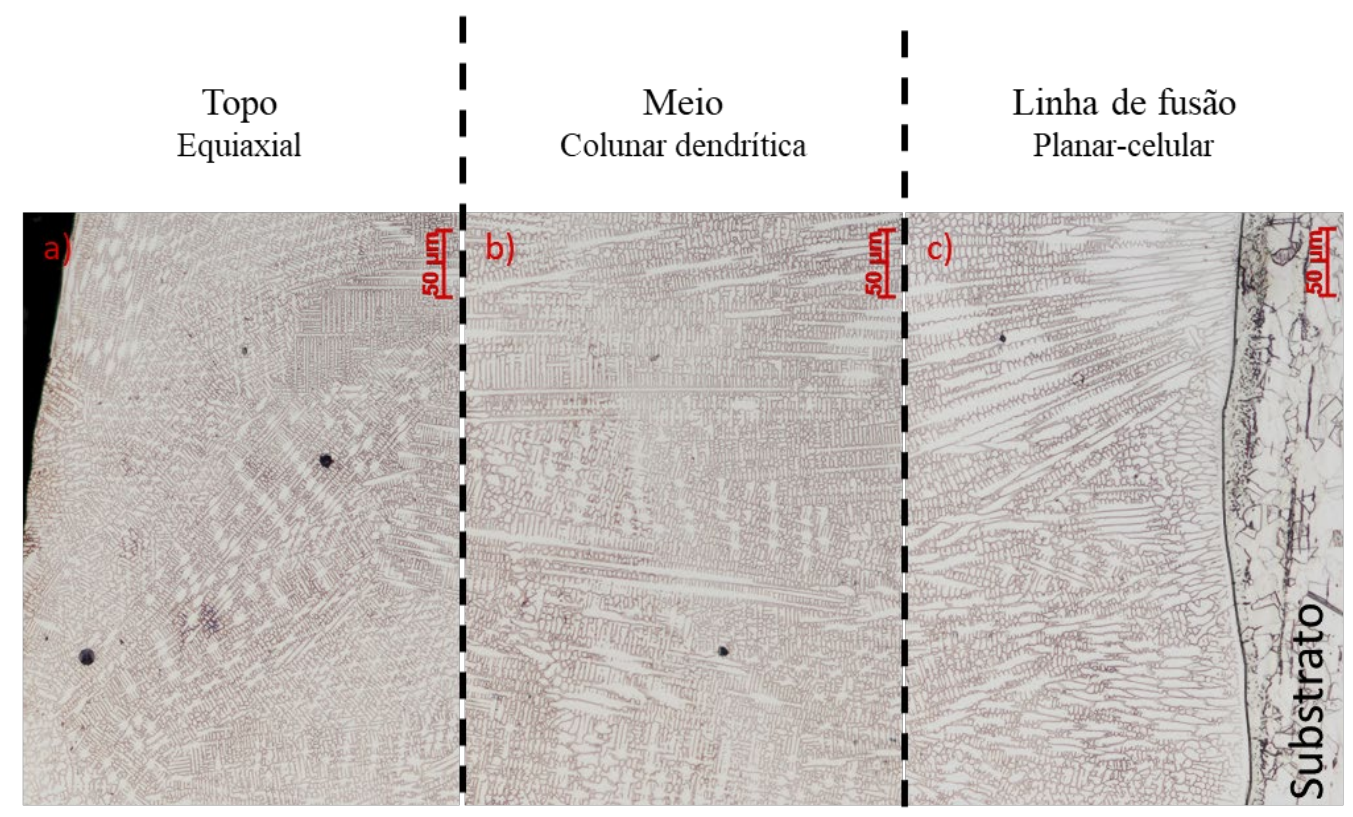

Figura 12. Variação da estrutura de solidificação ao longo da seção transversal dos revestimento obtidos nos teste de validação.

Em uma maior ampliação de outra região a Figura 13 exibe com mais detalhes a transição microestrutural que ocorre do substrato para o revestimento, na parte de baixo da figura é possível observar os grãos austeníticos característicos deste aço inoxidável, em direção ao topo da está região de transição composta por uma camada celular que se estende por todo revestimento indicada como interface planar. E finalmente adentrando o revestimento observa-se a presença de dendritas colunares quase que perpendiculares ao plano do substrato e a formação de dendritas equiaxiais [32].

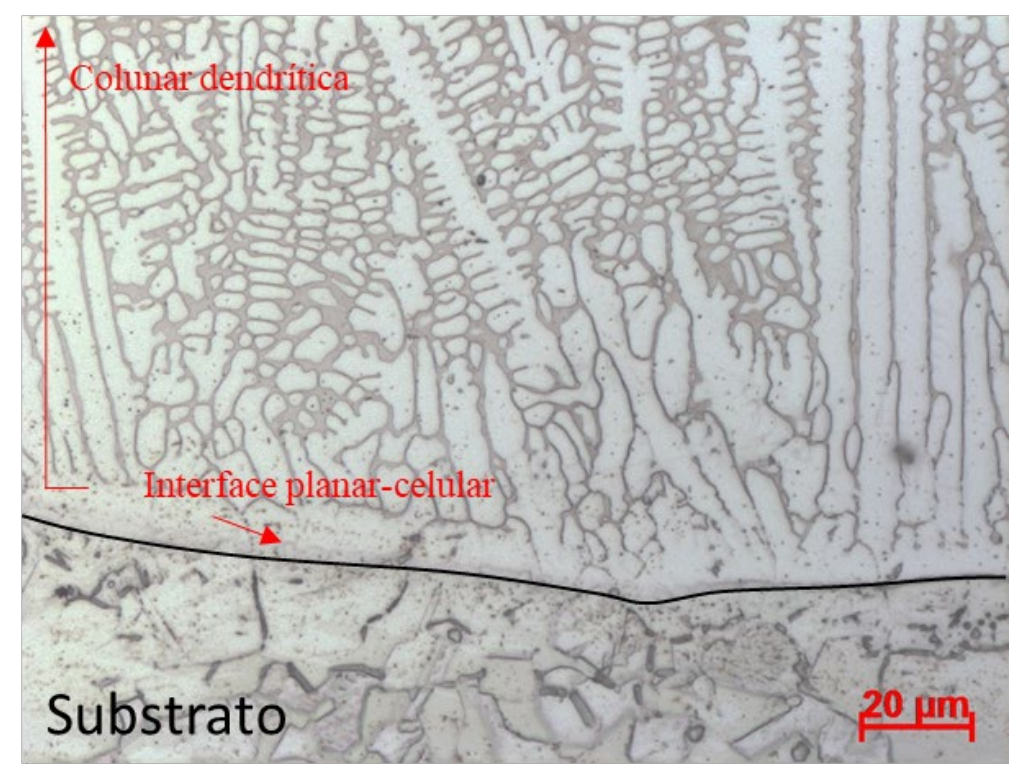

Figura 13. Mudança microestrutural da interface planar para revestimento colunar dendrítico. 
A deposição apresenta uma microestrutura dendrítica típica dos revestimentos de Stellites 6 processados a laser, como mostrado na Figura 12. Essa microestrutura é típica de uma liga hipoeutética, onde a primeira fase que se forma durante o resfriamento é a solução sólida dendrítica rica em Co, representada pela letra (A) na Figura 14, e o líquido restante se solidifica em uma reação eutética no espaço interdendrítico, consistindo em Co e carbonetos ricos em W e $\mathrm{Cr}$ [21].

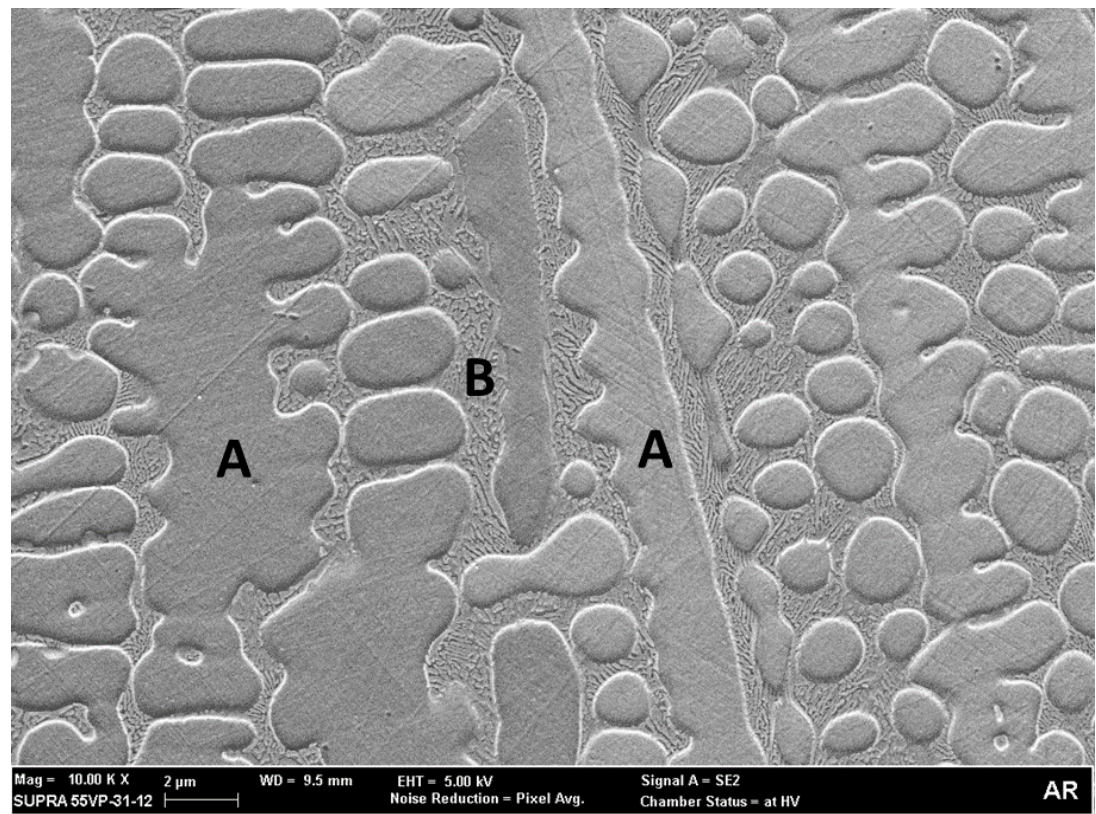

Figura 14. Microestrutura da seção transversal na região central do revestimento obtido nos testes de validação: (A) braço dendrítico rico em Co e (B) região interdendrítica composta por Co e carbonetos ricos em Cr e W.

Uma análise mais detalhada da microestrutura apresentada na Figura 15, evidencia a estrutura lamelar do constituinte eutético na região interdendrítica. Um mapa de composição química (EDS) confirma que a região interdendrítica é rica em Co, $\mathrm{Cr}$ e C. Yao et al. [33] obteve estruturas similares em seu estudo, que foram identificados como carbonetos de cromo do tipo $\mathrm{M}_{\mathrm{X}} \mathrm{C}_{\mathrm{x}}$ [34,35]. Corroborando também com o resultado apresentado em Ding et al. onde as regiões mais escuras possuem altas concentrações de carbono e cromo [17].
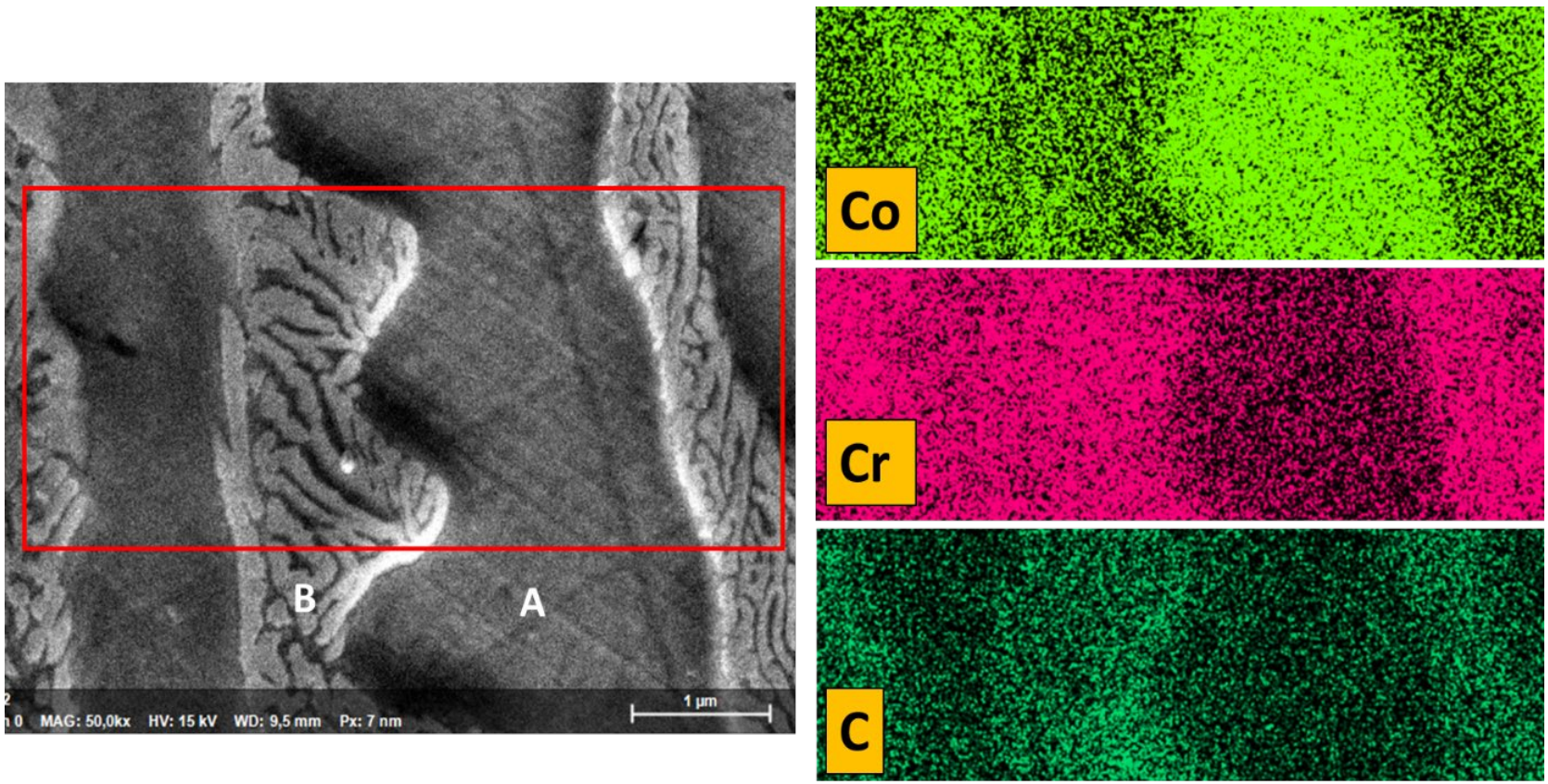

Figura 15. Imagem do MEV_FEG utilizando EDS (A) Estrutura dendrítica rica em cobalto e (B) estrutura lamelar rica em carbonetos de cromo. 


\section{Conclusões}

O presente trabalho teve o objetivo determinar parâmetros de processamento a laser para deposição de revestimentos de Stellite 6 livre de descontinuidades e com geometria adequado sobre aço inoxidável austenítico. Revestimentos foram depositados com diferentes potências do feixe laser e velocidades de deposição. A geometria (largura, altura, ondulação e diluição) dos revestimentos foi medida por meio de análise da secção transversal. Esses dados foram utilizados para a modelagem do processo (superfície de resposta) e para estimar parâmetros ótimos (função desejabilidade), que foram verificados experimentalmente. A partir dos resultados apresentados, os seguintes pontos podem ser destacados:

- Todas as condições de processamento resultaram em revestimentos contínuos e com boa adesão ao substrato sem ocorrência de desplacamento;

- $\quad$ Por meio do ensaio de LP verificou se uma tendência de surgimento de trincas para as condições de deposição com maior energia de linha $(\mathrm{J} / \mathrm{mm})$;

- A metodologia de superfície de resposta evidenciou que para uma dada velocidade de deposição e taxa de alimentação, quanto maior a potência do feixe laser, maior a diluição e menor a ondulação;

- A metodologia de superfície de resposta evidenciou que para uma dada potência do feixe laser e taxa de alimentação, menor a diluição e a altura média da camada;

- Por meio da função desejabilidade (otimização numérica) foram estimados parâmetros de deposição que resultaram em revestimentos com características adequadas (validação experimental);

- A microestrutura e dureza dos revestimentos estão em concordância com o que já foi reportado na literatura.

\section{Referências}

[1] Bartkowski D, Kinal G. Microstructure and wear resistance of Stellite-6/WC MMC coatings produced by laser cladding using Yb:YAG disk laser. International Journal of Refractory Metals \& Hard Materials. 2016;58:157-164. http://dx.doi.org/10.1016/j.ijrmhm.2016.04.017.

[2] Bartkowski D, Młynarczak A, Piasecki A, Dudziak B, Gos̈ciański M, Bartkowska A. Microstructure, microhardness and corrosion resistance of Stellite-6 coatings reinforced with WC particles using laser cladding. Optics \& Laser Technology. 2015;68:191-201. http://dx.doi.org/10.1016/j.optlastec.2014.12.005.

[3] Sun GF, Shen XT, Wang ZD, Zhan MJ, Yao S, Zhou R, et al. Laser metal deposition as repair technology for 316L stainless steel: influence of feeding powder compositions on microstructure and mechanical properties. Optics \& Laser Technology. 2019;109:71-83. http://dx.doi.org/10.1016/j.optlastec.2018.07.051.

[4] Li S, Li C, Deng P, Zhang Y, Zhang Q, Sun S, et al. Microstructure and properties of laser-cladded bimodal composite coatings derived by composition design. Journal of Alloys and Compounds, 2018;745:483-489. http://dx.doi.org/10.1016/j.jallcom.2018.02.165.

[5] Bartkowski D, Bartkowska A. Wear resistance in the soil of Stellite-6/WC coatings produced using laser cladding method. International Journal of Refractory Metals \& Hard Materials. 2017;64:20-26. http://dx.doi.org/10.1016/j.ijrmhm.2016.12.013.

[6] Zhong M, Liu W, Yao K, Goussain JC, Mayer C, Becker A. Microstructural evolution in high power laser cladding of Stellite 6+WC layers. Surface and Coatings Technology. 2002;157(2-3):128-137. http://dx.doi.org/10.1016/S0257-8972(02)00165-2.

[7] Donachie MJ, Donachie SJ. Superalloys: a technical guide. West Conshohocken: ASTM International; 2008.

[8] Davis JR. ASM specialty handbook: nickel, cobalt, and their alloys. Vol. 56. West Conshohocken: ASTM International; 2000.

[9] Bond D. Avaliação de revestimentos soldados processados com materiais atomizados. Arquivos de Neuro-Psiquiatria. 2011;69(3):441445.

[10] Crook, P. Cobalt and cobalt alloys. In: ASM Handbook Committee. Properties and selection: nonferrous alloys and special-purpose materials. Vol. 157. West Conshohocken: ASTM International; 1990. p. 446-454.

[11] Krell J, Röttger A, Theisen W. Comprehensive investigation of the microstructure-property relationship of differently manufactured Co$\mathrm{Cr}-\mathrm{C}$ alloys at room and elevated temperature. Wear. 2020;444-445:203138. http://dx.doi.org/10.1016/j.wear.2019.203138.

[12] Wang G, Zhang J, Shu R, Yang S. High temperature wear resistance and thermal fatigue behavior of Stellite-6/WC coatings produced by laser cladding with Co-coated WC powder. International Journal of Refractory Metals \& Hard Materials. 2019;81:63-70. http://dx.doi.org/10.1016/j.ijrmhm.2019.02.024.

[13] Wu Y, Liu Y, Chen H, Chen Y, Li H, Yi W. Microstructure evolution and crack propagation feature in thermal fatigue of laser-deposited Stellite 6 coating for brake discs. Surface and Coatings Technology, 2019;358:98-107. http://dx.doi.org/10.1016/j.surfcoat.2018.11.011.

[14] Karimi GN, Carrington MJ, Thomas J, Shipway PH, Stewart DA, Hussain T. The role of microstructural development in the hydrothermal corrosion of cast and HIPed Stellite 6 analogues in simulated PWR conditions. Corrosion Science. 2019;159:108141. http://dx.doi.org/10.1016/j.corsci.2019.108141. 
[15] Mostafaei A, Rodriguez De Vecchis P, Buckenmeyer MJ, Wasule SR, Brown BN, Chmielus M. Microstructural evolution and resulting properties of differently sintered and heat-treated binder-jet 3D-printed Stellite 6. Materials Science and Engineering C. 2019;102:276288. http://dx.doi.org/10.1016/j.msec.2019.04.011. PMid:31147000.

[16] Brownlie F, Hodgkiess T, Pearson A, Galloway AM. Effect of nitriding on the corrosive wear performance of a single and double layer Stellite 6 weld cladding. Wear. 2017;376-377:1279-1285. http://dx.doi.org/10.1016/j.wear.2017.01.006.

[17] Ding Y, Liu R, Yao J, Zhang Q, Wang L. Stellite alloy mixture hardfacing via laser cladding for control valve seat sealing surfaces. Surface and Coatings Technology. 2017;329:97-108. http://dx.doi.org/10.1016/j.surfcoat.2017.09.018.

[18] Houdková Š, Pala Z, Smazalová E, Vostrák M, Česánek Z. Microstructure and sliding wear properties of HVOF sprayed, laser remelted and laser clad Stellite 6 coatings. Surface and Coatings Technology. 2017;318:129-141. http://dx.doi.org/10.1016/j.surfcoat.2016.09.012.

[19] Li B, Jin Y, Yao J, Li Z, Zhang Q. Solid-state fabrication of WCp-reinforced Stellite-6 composite coatings with supersonic laser deposition. Surface and Coatings Technology. 2017;321:386-396. http://dx.doi.org/10.1016/j.surfcoat.2017.04.062.

[20] Derringer G, Suich R. Simultaneous optimization of several response variables. Journal of Quality Technology. 1980;12(4):214-219. http://dx.doi.org/10.1080/00224065.1980.11980968.

[21] Zhong C, Biermann T, Gasser A, Poprawe R. Experimental study of effects of main process parameters on porosity, track geometry, deposition rate, and powder efficiency for high deposition rate laser metal deposition. Journal of Laser Applications. 2015;27(4):042003. http://dx.doi.org/10.2351/1.4923335.

[22] Lupoi R, Cockburn A, Bryan C, Sparkes M, Luo F, O'Neill W. Hardfacing steel with nanostructured coatings of Stellite-6 by supersonic laser deposition. Light, Science \& Applications. 2012;1:1-6. http://dx.doi.org/10.1038/lsa.2012.10.

[23] de Oliveira U, Ocelík V, De Hosson JTM. Analysis of coaxial laser cladding processing conditions. Surface and Coatings Technology. 2005;197(2-3):127-136. http://dx.doi.org/10.1016/j.surfcoat.2004.06.029.

[24] Singh R, Kumar D, Mishra SK, Tiwari SK. Laser cladding of Stellite 6 on stainless steel to enhance solid particle erosion and cavitation resistance. Surface and Coatings Technology. 2014;251:87-97. http://dx.doi.org/10.1016/j.surfcoat.2014.04.008.

[25]ASTM International. ASTM E2109-01: Test Methods of Determining Area Percentage Porosity in Thermal Sprayed Coatings. West Conshohocken: ASTM; 2014.

[26] Luo F, Cockburn A, Lupoi R, Sparkes M, O’Neill W. Performance comparison of Stellite $6^{\circledR}$ deposited on steel using supersonic laser deposition and laser cladding. Surface and Coatings Technology. 2012;212:119-127. http://dx.doi.org/10.1016/j.surfcoat.2012.09.031.

[27] Sun S, Durandet Y, Brandt M. Parametric investigation of pulsed Nd: YAG laser cladding of stellite 6 on stainless steel. Surface and Coatings Technology. 2005;194(2-3):225-231. http://dx.doi.org/10.1016/j.surfcoat.2004.03.058.

[28] Kusmoko A, Dunne D, Li H, Nolan D. Effect of two different energy inputs for laser cladding of stellite 6 on P91 and P22 steel substrates. Procedia Materials Science, 6, 26-36, 2014. http://dx.doi.org/10.1016/j.mspro.2014.07.005.

[29] Ion J. Laser processing of engineering materials. Burlington: Elsevier B.V; 2005.

[30] Steen WM, Mazumder J. Laser material processing. London: Springer; 2010. http://dx.doi.org/10.1007/978-1-84996-062-5.

[31] Kou S. Welding metallurgy. New York: Wiley-Interscience; 2003. p. 431-446.

[32] D'Oliveira ASCM, Da Silva PSCP, Vilar RMC. Microstructural features of consecutive layers of Stellite 6 deposited by laser cladding. Surface and Coatings Technology. 2002;153(2-3):203-209. http://dx.doi.org/10.1016/S0257-8972(01)01687-5.

[33] Yao J, Zhang J, Wu G, Wang L, Zhang Q, Liu R. Microstructure and wear resistance of laser cladded composite coatings prepared from pre-alloyed WC-NiCrMo powder with different laser spots. Optics \& Laser Technology. 2018;101:520-530. http://dx.doi.org/10.1016/j.optlastec.2017.12.007.

[34] Farnia A, Malek Ghaini F, Ocelík V, De Hosson JTM. Microstructural characterization of Co-based coating deposited by low power pulse laser cladding. Journal of Materials Science. 2013;48(6):2714-2723. http://dx.doi.org/10.1007/s10853-012-7069-8.

[35]Foltran BDB, Kuwabara EY, D'Oliveira ASCM. Caracterização de revestimentos de stellite 6 depositados por eletrodo revestido, soldagem por arco transferido a plasma e laser. In: Anais do XV Congresso Brasileiro de Engenharia Mecânica; 1999 Novembro 22-26; Água de Lindóia, São Paulo. Rio de Janeiro: ABCM; 1999. p. 11. 